\section{OPEN ACCESS}

Edited by:

Josefa Leon,

Fundación para la Investigación

Biosanitaria de Andalucía Orienta (FIBAO), Spain

Reviewed by:

Karel Pacak,

National Institutes of Health (NIH), United States

Tarek Francis Antonios,

St George's, University of London, United Kingdom

*Correspondence: Lasse D. Jensen lasse.jensen@liu.se

Specialty section:

This article was submitted to

Cancer Endocrinology

a section of the journal

Frontiers in Endocrinology

Received: 15 June 2018

Accepted: 26 September 2018

Published: 16 October 2018

Citation:

Tabebi M, Söderkvist $P$ and Jensen LD (2018) Hypoxia Signaling and Circadian Disruption in and by

Pheochromocytoma.

Front. Endocrinol. 9:612

doi: 10.3389/fendo.2018.00612

\title{
Hypoxia Signaling and Circadian Disruption in and by Pheochromocytoma
}

\author{
Mouna Tabebi ${ }^{1}$, Peter Söderkvist ${ }^{1}$ and Lasse D. Jensen ${ }^{2 *}$ \\ ${ }^{1}$ Department of Clinical and Experimental Medicine, Linköping University, Linköping, Sweden, ${ }^{2}$ Department of Medicine and \\ Health Science, Linköping University, Linköping, Sweden
}

Disruption of the daily (i.e., circadian) rhythms of cell metabolism, proliferation and blood perfusion is a hallmark of many cancer types, perhaps most clearly exemplified by the rare but detrimental pheochromocytomas. These tumors arise from genetic disruption of genes critical for hypoxia signaling, such as von Hippel-Lindau and hypoxia-inducible factor-2 or cellular metabolism, such as succinate dehydrogenase, which in turn impacts on the cellular circadian clock function by interfering with the Bmal1 and/or Clock transcription factors. While pheochromocytomas are often nonmalignant, the resulting changes in cellular physiology are coupled to de-regulated production of catecholamines, which in turn disrupt circadian blood pressure variation and therefore circadian entrainment of other tissues. In this review we thoroughly discuss the molecular and physiological interplay between hypoxia signaling and the circadian clock in pheochromocytoma, and how this underlies endocrine disruption leading to loss of circadian blood pressure variation in the affected patients. We furthermore discuss potential avenues for targeting these tumor-specific pathophysiological mechanisms therapeutically in the future.

Keywords: pheochromocytoma, circadian, hypoxia, cancer, blood pressure, catecholamines

\section{INTRODUCTION}

Cancer is a growing health threat exhibiting relentlessly increasing incidence due to changes in the pro-tumorigenic environmental stressors of our modern lifestyle as well as improved longevity, screening programs and diagnostic capabilities. This increase in incidence is particularly evident for rare, endocrine-disrupting cancers such as pheochromocytomas (PCCs), exhibiting an incidence of approximately 5 cases per million life-years in Scandinavia (1). As the pathology and treatment of PCC, as well as other rare cancers are poorly understood, there is a need for more investigations into these types of cancer. PCC is characterized by endocrine disruption in the patient, primarily evident as pathogenic, non-circadian blood pressure dysregulation (2). As such, PCC clearly interferes with circadian, endocrine regulation of cardiovascular physiology. On the other hand, disruptions in circadian physiology may also lead to stress and de-regulation of the chromaffin cells, potentially increasing the risk of PCC development (3). In addition, PCC pathology is often genetically linked to disrupted oxygen sensing and hypoxia signaling $(1,4)$, which in turn is intimately coupled to regulation of the cellular circadian clock (5) and to endocrine as well as local regulation of cardiovascular function and metabolism (6). As such, PCC represents a malignancy in which multiple aspects of hypoxia and circadian regulation of endocrine functions 
are affected, providing a strong case for understanding such interplay in more detail. In this review we discuss the molecular and physiological basis for crosstalk between the endocrine, metabolic and cardiovascular systems, hypoxia signaling and the circadian clock in the context of PCC, highlighting bilateral interactions between these systems, which in many cases are also relevant for other cancer types.

\section{PHEOCHROMOCYTOMA}

Pheochromocytoma (PCC) is a catecholamine-producing tumor of chromaffin cells typically located in the adrenals. Most patients present with benign tumors, but as both benign and malignant tumors produce large amounts of endocrinedisrupting hormones, we will not differentiate between these two different classes in this review. They are characterized by an abnormally high production of catecholamines causing persistent or paroxysmal hypertension recurrent episodes of headache, palpitations and sweating, and an increased risk of cardiovascular disease (7). Germline and somatic genetic alterations in a growing number of genes are associated with PCC development and the major susceptibility genes are; the von Hippel-Lindau (VHL) tumor-suppressor protein, the rearranged during transfection (RET) protooncogene, the neurofibromatosis type 1 (NF1) tumor suppressor gene, genes encoding the four subunits $(\mathrm{A}, \mathrm{B}, \mathrm{C}$, D) of the succinate dehydrogenase $(S D H)$ complex and the gene encoding the enzyme responsible for flavination of the SDHA subunit (SDHAF2), and in rare occasions the egl-9 family hypoxia-inducible factor1/ Prolyl hydroxylase domain 2 protein (EGLN1/PHD2) tumor suppressor. Recently, three other genes, transmembrane protein 127 (TMEM127), MYCassociated factor $\mathrm{X}(M A X)$, and hypoxia-inducible factor $2 \alpha$ (HIF2 $\alpha$ / EPAS1) have been described to be mutated or amplified $(1,4,8-10)$. The known germline and somatic mutations account for the pathogenesis of approximately $60 \%$ of PCC (7). Approximately, $30 \%$ of pheochromocytomas are hereditary and caused by mutations in well-known susceptibility genes $(1,11,12)$. Interestingly, many sporadic pheochromocytomas have somatic mutations limited to only one of these hereditary genes, indicating that they may be the main driver. However, the cause of many sporadic tumors is still unknown $(1,8,13)$. The most commonly mutated genes are found in the SDH complex, SDHD (87.1\%), followed by SDHAF2 (6.7\%), SDHB (5.9\%) and SDHC $(0.3 \%)$. About $20 \%$ of tumors have mutations in the NF1 gene, about $14 \%$ in the RET and VHL genes, $5-10 \%$ in HRAS but only 2.5 and $1.65 \%$ of the tumors present HIF2A and MAX mutations, respectively $(7,14-16)$.

Based on the main signaling pathway signatures resulting from hereditary and sporadic pheochromocytoma gene mutations, pheochromocytomas are divided in two main gene expression clusters (17-19): The first group, pseudo-hypoxia cluster, included tumors carrying SDHx (cluster 1A) and $V H L$ (cluster 1B) mutations, which accounts for $30 \%$ of the sporadic tumors. In addition, mutations in fumarate hydratase $(F H)$ (cluster 1A) and HIF2A (cluster 1B) are characterized by transcription signatures suggesting reduced oxidoreductase activity and increased hypoxia and angiogenesis (Figure 1). The second cluster represents expression signatures of mutated genes in kinase receptor signaling and protein translocation pathways, i.e., the RET- and NF1- related pheochromocytomas and includes $70 \%$ of the sporadic tumors. Cluster 2 can be divided into subcluster $2 \mathrm{~A}, 2 \mathrm{~B}, 2 \mathrm{C}$ and $2 \mathrm{D}$. Subcluster $2 \mathrm{~A}$ comprises RET, MAX, NF1 and TMEM127 mutated tumors, subcluster $2 \mathrm{~B}$ and $2 \mathrm{C}$ include sporadic tumors and cluster $2 \mathrm{D}$ include tumors lacking known mutations related to PCC. Cluster 2 mediate translation initiation, protein synthesis, adrenergic metabolism, neural/neuroendocrine differentiation and kinase signaling (Figure 1).

\section{HIF in Cluster 1 PCCs}

Cluster 1 tumors are mostly extra-adrenal, expect for $V H L$ tumors which usually are adrenal (20). SDH-related tumors, especially those associated with $S D H B$, are more aggressive and prone to metastasis than VHL PCCs that shows a low risk of malignancy (21). Mutations in VHL cause VHL disease. In presence of oxygen, The VHL protein (pVHL) is the substrate recognition unit of the $\mathrm{VBC}$ E3 ubiquitin ligase complex that target HIF for proteasomal degradation. HIF- $1 \alpha$ and $-2 \alpha$ are hydroxylated by PHD under normoxic conditions, which is recognized by pVHL for ubiquitination (22). Mutations in VHL that cause VHL disease leads to the production of a pVHL that is not able to recognize hydroxylated HIFs resulting in stabilized and therefore increased levels of HIF and HIFassociated transcription of target genes (18, 23-25).

$\mathrm{SDH}$-related tumorigenesis is also associated with the HIF pathway (activation and stability) (26). SDHx is a part of complex 2 in the mitochondrial respiratory chain and when mutated disrupts the activity and stability of the SDH enzyme resulting in succinate accumulation. As PHD hydroxylation activity requires the conversion of $\alpha$-ketoglutarate to succinate (27), succinate accumulation inhibits PHD-catalyzed HIF-1/2 $\alpha$ hydroxylation (28), potentially leading to hypoxia signaling in the PCC cells.

Several findings support the leading role of HIF- $2 \alpha$ in development and progression of cluster 1 tumors $(18,29)$. Patients with PCCs carrying SDHB or SDHD mutations, present an overexpression of HIF- $2 \alpha$ and transcriptional targets like VEGF found in PCCs $(29,30)$. In addition, the accumulation of succinate as a result of tumors carrying $\mathrm{FH}$ mutations displays the $\mathrm{CpG}$ island methylator phenotype (CIMP), the same pattern of epigenetic deregulation as SDHB-mutated malignant PCC (31).

All PCC with HIF2A/EPAS1 mutations showed higher expression of EPAS1 and HIF-2 $\alpha$ target genes e.g $\operatorname{VEGF}(4,10$, $15,32)$. However, the reason or the mechanisms are still not clear. The mutational analysis of EPAS1 gene by sequencing of exon 9 and 12 , which contain the two hydroxylation sites involved in HIF- $2 \alpha$ degradation, showed that more than $12 \%$ of PCC with isolated, non-familial tumors present several missense EPAS1 mutations in this region $(4,33)$.

\section{HIF in Cluster 2 PCCs}

Cluster 2 tumors are mostly adrenal, except for MAX/related tumors, with a low risk of malignancy (14). In MEN2 


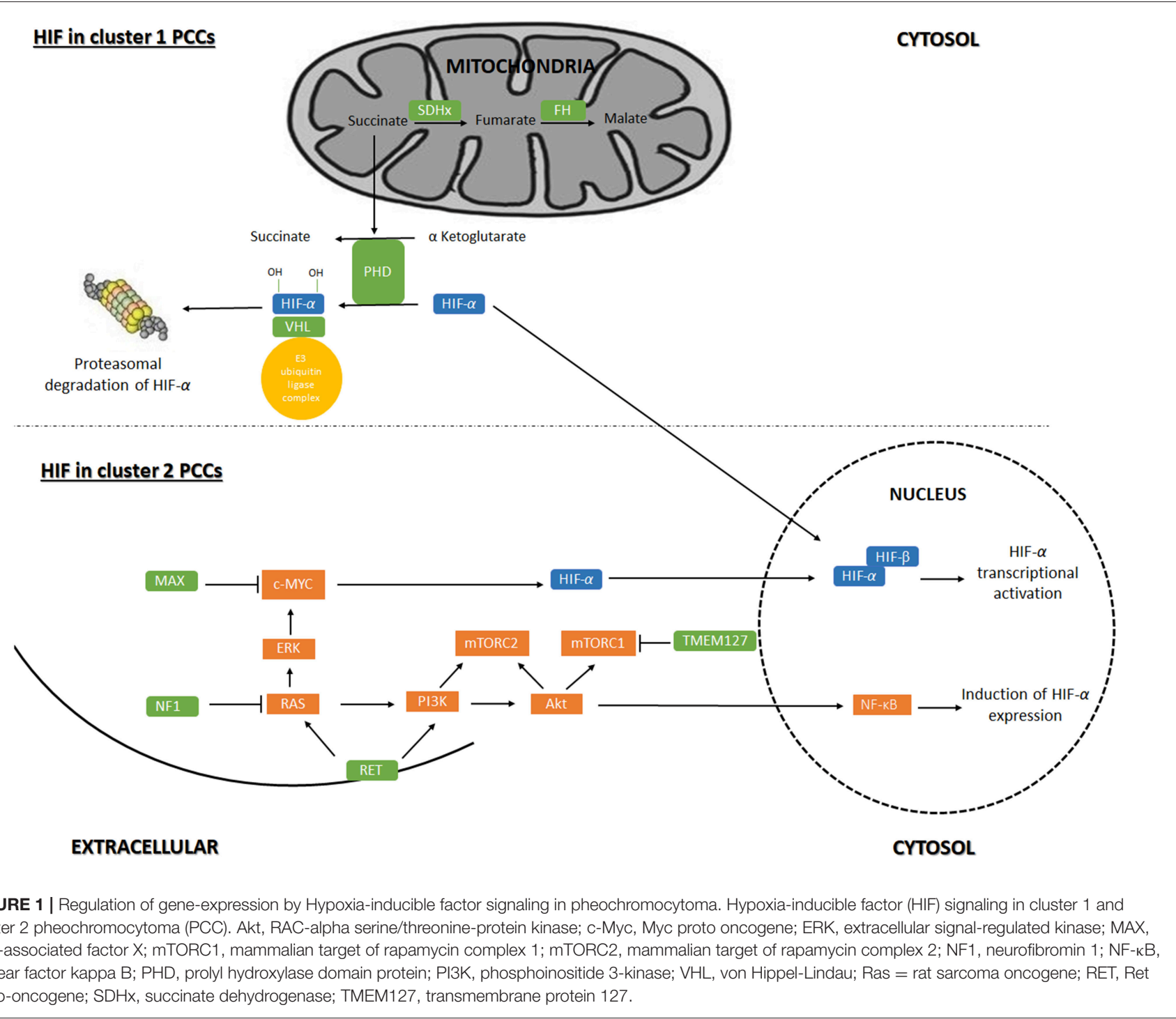

and NF1 syndromic cases, the RET and NFlinactivating mutations causes the activation of Ras/MAPK and PI3K/AKT pathways (34). In tumors caused by TMEM127 and MAX mutations, mTORC activation could increase HIF-1/2 $\alpha$ levels (35): Mutations in TMEM127 gene lead to enhancement of mTORC signaling in a Ras- and PI3K/AKT-independent manner(36). Mutations in MAX deregulate c-MYC signaling of which HIF- $1 \alpha$ is a downstream target (33). Thus, crosstalk between the Myc/MAX/MXD1 (MAX-interacting protein 1) and Ras/PIK3/AKT1/mTORC has been proposed (37), suggesting that MAX affects the mTORC pathway as well (18). K-RAS and $H$-RAS mutations were found in PCCs, causing the activation of the Ras/RAF/ERK signaling pathway, a part of the Ras/MAPK pathway (38). Ras/MAPK pathway activation leads to an increase in HIF- $1 / 2 \alpha$ signaling and the transcription of HIF target genes.

Despite the characterization of these two main groups a comprehensive molecular distinction between VHL- and SDHxrelated tumors on one hand and RET- and NF1- related tumors on the other hand, has not been achieved, as pseudohypoxia signaling may also be present in the latter sub-group. However, VHL tumors could be distinguished, for example, from SDHx tumors by transcription profiling, using restricted lists of genes involved in hypoxia (19) or glycolytic (23) pathways.

\section{HIF IN PCC DEVELOPMENT}

Hypoxia-inducible factors belong to the basic helix loop helix-PER-ARNT-SIM (bHLH-PAS) family of transcriptional regulators and have a similar protein domain structure as circadian rhythm regulators (39). HIFs are highly conserved proteins composed of $\alpha$ and $\beta$ subunits, that respond to changes in tissue oxygen concentration. The HIF- $\alpha$ subunits (HIF- $1 \alpha$, HIF- $2 \alpha$ and HIF-3 $\alpha$ ) are stabilized by hypoxia, as described above, whereas the HIF- $\beta$ subunit is constitutively expressed (39, 40). Under hypoxia, stabilized HIF- $\alpha$ subunits dimerize with ARNT (aryl hydrocarbon nuclear translocator) and activate 
transcription of genes involved in the hypoxia response such as apoptosis, glycolysis, cell growth and proliferation (41).

The HIF pathway was previously found to be dysfunctional in PCC tumors (26). Indeed, most of the hereditary PCCs are related to the hypoxia signaling pathway by increasing the stability of HIF, through the mutations within the $F H$, SDHx, SDHAF2, VHL, and PHD2 genes. SDHx mutations increase the stability of HIFs and the expression of their targets $(15,30)$. The $S D H x$ gene mutations result in the functional inactivation of the SDH complex results in the intracellular accumulation of succinate, which is converted by the PHDs from $\alpha$-ketoglutarate. This accumulated substrate in turn inhibits the PHDs because of its structural similarity with $\alpha$ ketoglutarate. Since the stability of the HIF- $\alpha$ subunits depends on their hydroxylation by PHDs, the SDHx mutation leading to inhibition of PHD will prevent degradation of HIF(42). In addition, the knockdown of SDHA or SDHB in cell lines leads to the inhibition of $\alpha$-ketoglutarate-dependent enzymes. This leads to hypermethylation of histones and DNA which also result in HIF- $\alpha$ accumulation and strong expression of HIF targets (42).

Several recent studies have also proposed that the PCCs mutations of NF1, RET, HRAS resulting in a cluster 2 type of gene expression pattern also connects to HIF signaling and acts on the same signaling network, resulting in i.e decreased apoptosis during chromaffin cell development and tumor formation. Moreover, cluster 2 gene mutations seem to enhance HIF- $2 \alpha$ signaling in cells $(18,43,44)$.

Deregulation of HIF- $\alpha$, specifically HIF-2 $\alpha$, has long been implicated in tumorigenesis and in poor prognosis of other human cancers as well as PCC (25). In particular, HIF-2 $\alpha$ activation was shown to be both necessary and sufficient for development of VHL-null renal cell carcinomas $(45,46)$.

\section{HYPOXIA AND THE CIRCADIAN CLOCK-TO SIDES OF THE SAME COIN?}

Hypoxia signaling and the circadian clock are closely related and heavily cross-communicating pathways (5). Both pathways are evolutionarily ancient, presenting the first molecular mechanisms allowing living organisms to adapt to environmental stimuli on earth (light/dark cycles and the strongly oxidative environment respectively) (47-50). Interestingly, the core components of these pathways belong to the same family of transcription factors and are regulated in a very similar fashion. Both the central mediators of hypoxia signaling, HIF- $1 \alpha$, HIF- $2 \alpha$, HIF-1 $\beta$ (ARNT), discussed above, and the core clock proteins Clock, Bmall and Period belong to the bHLH-PAS family of heterodimerizing transcription factors. They furthermore interact with each other to elicit induction or repression of transcription at the promotor regions of target genes $(5,51)$. This implies that HIF-1 $\beta$ can interact with either HIF- $1 \alpha$ or Clock, and Bmall can interact with either Clock or HIF-1 $\beta$ leading to the formation of either canonical hypoxia or circadian transcription factors, or mixed hypoxia/circadian transcription factors respectively $(51,52)$. In addition, the HIF-consensus DNA-binding motif ((A/G)CGTG), called the hypoxia-responsive element (HRE) (40) is similar to and included within the clock-consensus DNA-binding motif CACGTG, called the E-box (53). E-boxes are therefore also HREs, meaning that HIF-1 compete with Bmall/Clock heterodimers for binding and activation of clock-controlled gene transcription $(6,54)$ and some HREs are also E-boxes, meaning that Bmal1/Clock heterodimers may induce or disrupt HIF-mediated transcription (55). Accordingly, hypoxia-induced signaling is disrupted in circadian clock-deficient animals and circadian signaling is disrupted by hypoxia (56). As an example of this cross-talk, one of the archetypical hypoxiainduced genes coding for vascular endothelial growth factor (VEGF) was recently found to be completely subject to circadian control by Bmal1 and negatively regulated by Period2 in zebrafish embryos, leading to a circadian regulation of developmental angiogenesis(57, 58). Furthermore, the DNAbinding affinities of heterodimeric circadian transcription factor complexes Clock1:Bmal1 and Clock2:Bmal1 are highly sensitive to redox-modifications, exhibiting much higher E-box binding and transcriptional activity in the reduced state, suggesting that cellular oxidative stress, which is often associated with prolonged hypoxia, impairs the circadian clock (59). The disruption of circadian signaling by hypoxia was recently found to depend on lactic-acid mediated acidification, via disruption of mTORC1 signaling, possibly pin-pointing the molecular intersection between these two pathways and suggesting that their intimate cross-talk can be uncoupled by interfering with lactic acid metabolism and mTOR/mTORC1 activity (60). Additional similarities such as the importance of ubiquitinmediated destruction of circadian factors (61) and their crosstalk through transcription-translation negative feedback loops (5) have been excellently reviewed elsewhere.

\section{PHEOCHROMOCYTOMAS AFFECT CIRCADIAN RHYTHMS}

Epidemiological evidence have provided correlative evidence linking sleep disturbances in night shift workers to increased incidence and poor prognosis in hormonal cancers (62-64). The circadian rhythm is tightly connected to cell division and act as an additional checkpoint to determine the timing of mitosis. Certain stem cells may also synchronize their cell division due to rhythmic secretion of mitogens from adjacent cells. The circadian clock genes thus act as tumor suppressor genes and disruption of expression uncouples the control of the cell cycle from the circadian clock and promotes carcinogenesis (65). The suppression of circadian clock transcription factors in breast and prostate cancer cells is important for their malignant transformation and deletion of PER1 and PER2 in mice results in salivary gland tumor formation (62). Several oncogenic pathways such as cell cycle regulators and tumor suppressors are deregulated and associated to the circadian clock (66), such as the increased activity of Ras pathway (67). Overexpression of MYC is directly controlled by circadian proteins and upregulated in Per2 mutant mice and was recently shown to be a co-repressor 
of EMT (Epithelial-Mesenchymal Transition) (68). Further, upregulated MYC in different cancers silence the circadian clock and promotes cell proliferation while downregulation of MYC activates the clock and reduces proliferation (69).

As mentioned above, PCC is a pseudohypoxic tumor due to genetic disruption of the hypoxia signaling pathway (i.e., mutation in VHL), or due to mutations causing deficiencies in metabolic intermediates required for hydroxylation-mediated degradation of HIF1 $\alpha$. However, PCC is also a tumor type with high density, heavily disrupted and pathological blood vessels regardless of malignancy (70), indicating that blood flow is disrupted, further contributing to the hypoxic and acidic status of the tissue. This likely disrupts the circadian entrainment of the PCC cells (and non-malignant PCC stroma cells) by endocrine factors, contributing to disease progression.

The process of malignant transformation can furthermore affect circadian rhythms in distal, non-malignant tissues and organs, by introducing an imbalance in metabolic homeostasis of the body (65). For example, arrhythmic liver metastases of colorectal cancer were found to shift the phase of clock gene expression in healthy liver tissue (6). Similarly, a study on mice with pulmonary adenocarcinomas demonstrated that these caused alterations in hepatic circadian metabolism. In fact, the expression of the basic genes of the clock remains unchanged, while lung tumors specifically affected the oscillations of genes and molecules related to liver metabolism (71).

Circadian rhythms in the body are also affected by tumors that produce hormones such as PCC. Patients with adrenalineproducing PCC have circadian changes in blood pressure (BP) $(2,72)$. The attenuation of circadian blood pressure variation was more pronounced in PCC compared, for example, to steroidinduced adrenal hypertension (primary aldosteronism and Cushing syndrome). In fact, elevated catecholamine production in primary aldosteronism likely maintains a circadian rhythm, which is not the case in PCC, and this could be the reason for why diminished diurnal BP variation can only be observed in PCC, in spite of very high catecholamine production in both types of patients (72-74). Circadian rhythms in catecholamine production and secretion are closely linked to diurnal blood pressure variation in healthy adults $(75,76)$. Moreover, it was previously reported that normal subjects show a circadian rhythm in BP, with the highest values in the morning and the lowest at night (46). Asymptomatic subjects with pheochromocytoma and controls group did not differ in the office BP, but they differed significantly in the 24-h systolic and diastolic BP and also in the relative systolic and diastolic night-time BP decline (2).

In the case of PCC, alterations of sympathetic vascular regulation is the main cause of the pathogenesis of orthostatic hypotension, whereas cardiac vagal regulation acts to compensate for it (77). In fact, the tendency to the orthostatic hypotension with normal baroreflex is the most important factor contributing to the change in altered or inverted circadian BP. It causes a decrease in BP and increases the heart rate during the active period of the day more significantly than during the night (72, $77,78)$. These observations reflect higher sympathetic tonus than in normosensitive and hypertensive patients.
Zelinka et al. showed that circadian BP variation is reduced in both patients with asymptomatic normotensive PCC and patients with typical, hypertensive PCC to the same degree (2). However, only the mechanisms responsible for circadian $\mathrm{BP}$ disruption in hypertensive patients with PCC has been described previously $(2,74)$, and the mechanisms by which PCC leads to loss of circadian BP therefore remains incompletely understood (74). The reduction of circadian BP rhythm may be due to the partial desensitization of the cardiovascular system to catecholamines in PCC is insufficient $(2,72,79)$.

Depending on expression of biosynthetic enzymes (80, 81), constitutive or regulated secretory pathways (82), PCC tissues produce different concentrations of catecholamines. Recently, new evidences confirmed the existence of mutationdependent biochemical phenotypes in PCCs: all MEN2 and NF1 tumors are characterized by increased plasma concentrations of metanephrine. Usually, VHL tumors present with increases in normetanephrine and $70 \%$ of patients with $S D H$ mutations are characterized by additional increases in methoxytyramine (82). However, some patients with high levels of circulating catecholamines associated with nocturnal changes in blood pressure, are not hypertensive, suggesting that other regulatory mechanisms associated with circadian fluctuation of blood pressure, such as the sympathetic nervous system and/or the hypothalamic-pituitary-adrenal system are still active and important in PCC patients (83). It should also be noted that about $15-20 \%$ of patients with PCC, presented a normal concentration of catecholamines (79). Most of these cases are explained by the non-secretion of the significant amounts of catecholamines which are called "non-functional" or "silent" PCC (81). The lack of catecholamine secretion in biochemically silent PCC is not due to defects in the mechanisms of storage or secretion of catecholamines but to the absence of tyrosine hydroxylase ( $\mathrm{TH})$, the initial and rate limiting enzyme in catecholamine formation. This phenotype appears to be associated with mutations of the SDHB gene (84). In most PCC cases, however, previously modified circadian BP variation is improved after successful tumor removal, or medical treatment (72).

\section{CONCLUSION AND FUTURE PROSPECTS}

Pheochromocytomas are chromaffin cell tumors that arise from the adrenal medulla. The dysfunction of genes involved in the cellular response to hypoxia, such as VHL, EGL nine homolog 1 , and the succinate dehydrogenase (SDH) genes, leads to direct abrogation of hypoxia-inducible factor (HIF) degradation, resulting in a pseudo-hypoxia state implicated in PCC development (33). HIF $\alpha$ signaling is hypothesized to be an effective signaling pathway involved in the pathogenesis of hereditary and sporadic PCC and other neuroendocrine tumors. $\mathrm{HIF} \alpha$ is a very promising therapeutic target, particularly for aggressive and metastatic tumors where the introduction of HIF- $2 \alpha$ inhibitors is of prime interest at present. Recently, many agents affecting HIF1 $\alpha$ signaling have been introduced, leading to different 
results depending on a cancer HIF $\alpha$ phenotype (85). Otherwise, drugs targeting the HIF-2 $\alpha$ signaling pathways have not yet been described but are currently under development $(86,87)$.

\section{AUTHOR CONTRIBUTIONS}

PS and LJ outlined the content and supervised the Project. MT and LJ performed research and wrote the

\section{REFERENCES}

1. Welander J, Soderkvist P, Gimm O. Genetics and clinical characteristics of hereditary pheochromocytomas and paragangliomas. Endocr Relat Cancer (2011) 18:R253-276. doi: 10.1530/ERC-11-0170

2. Zelinka T, Widimsky J, Weisserova J. Diminished circadian blood pressure rhythm in patients with asymptomatic normotensive pheochromocytoma. Physiol Res. (2001) 50:631-4.

3. Antoni $\mathrm{MH}$, Lutgendorf SK, Cole SW, Dhabhar FS, Sephton SE, McDonald PG, et al. The influence of bio-behavioural factors on tumour biology: pathways and mechanisms. Nat Rev Cancer (2006) 6:240-8. doi: $10.1038 / \mathrm{nrc1} 1820$

4. Welander J, Andreasson A, Brauckhoff M, Backdahl M, Larsson C, Gimm O, et al. Frequent EPAS1/HIF2alpha exons 9 and 12 mutations in non-familial pheochromocytoma. Endocr Relat Cancer (2014) 21:495-504. doi: 10.1530/ERC-13-0384

5. Jensen LD. The circadian clock and hypoxia in tumor cell dedifferentiation and metastasis. Biochim Biophys Acta (2015) 1850:1633-41. doi: 10.1016/j.bbagen.2014.10.025

6. Peek CB, Levine DC, Cedernaes J, Taguchi A, Kobayashi Y, Tsai SJ, et al. Circadian Clock Interaction with HIFlalpha mediates oxygenic metabolism and anaerobic glycolysis in skeletal muscle. Cell Metab. (2017) 25:86-92. doi: 10.1016/j.cmet.2016.09.010

7. Pillai S, Gopalan V, Smith RA, Lam AK. Updates on the genetics and the clinical impacts on phaeochromocytoma and paraganglioma in the new era. Crit Rev Oncol Hematol. (2016) 100:190-208. doi: 10.1016/j.critrevonc.2016.01.022

8. Bausch B, Schiavi F, Ni Y, Welander J, Patocs A, Ngeow J, et al. Clinical Characterization of the Pheochromocytoma and Paraganglioma Susceptibility Genes SDHA, TMEM127, MAX, and SDHAF2 for Gene-Informed Prevention. JAMA Oncol. (2017) 3:1204-12. doi: 10.1001/jamaoncol.2017.0223

9. Daly AF, Castermans E, Oudijk L, Guitelman MA, Beckers P, Potorac I, et al. Pheochromocytomas and pituitary adenomas in three patients with MAX exon deletions. Endocr Relat Cancer (2018) 25:L37-42. doi: 10.1530/ERC-18-0065

10. Zhuang Z, Yang C, Lorenzo F, Merino M, Fojo T, Kebebew E, et al. Somatic HIF2A gain-of-function mutations in paraganglioma with polycythemia. $N$ Engl J Med. (2012) 367:922-30. doi: 10.1056/NEJMoa1205119

11. Fishbein L, Leshchiner I, Walter V, Danilova L, Robertson AG, Johnson AR, et al. Comprehensive molecular characterization of pheochromocytoma and paraganglioma. Cancer Cell. (2017) 31:181-93. doi: 10.1016/j.ccell.2017.01.001

12. Neumann HP, Bausch B, McWhinney SR, Bender BU, Gimm O, Franke G, et al. Germ-line mutations in nonsyndromic pheochromocytoma. N Engl J Med. (2002) 346:1459-66. doi: 10.1056/NEJMoa020152

13. Burnichon N, Vescovo L, Amar L, Libe R, de Reynies A, Venisse $A$, et al. Integrative genomic analysis reveals somatic mutations in pheochromocytoma and paraganglioma. Hum Mol Genet. (2011) 20:3974-85. doi: $10.1093 / \mathrm{hmg} / \mathrm{ddr} 324$

14. Burnichon N, Buffet A, Parfait B, Letouze E, Laurendeau I, Loriot C, et al. Somatic NF1 inactivation is a frequent event in sporadic pheochromocytoma. Hum Mol Genet. (2012) 21:5397-405. doi: 10.1093/hmg/dds374 manuscript. All authors read, revised and approved the manuscript.

\section{FUNDING}

This work was supported by the Swedish Society for Medical Research, the Ollie and Elof Ericssons Foundation, The Swedish Research Council, The Swedish Cancer Foundation and Linköping University.

15. Toledo RA, Qin Y, Srikantan S, Morales NP, Li Q, Deng Y, et al. In vivo and in vitro oncogenic effects of HIF2A mutations in pheochromocytomas and paragangliomas. Endocr Relat Cancer (2013) 20:349-59. doi: 10.1530/ERC-13-0101

16. Welander J, Larsson C, Backdahl M, Hareni N, Sivler T, Brauckhoff $\mathrm{M}$, et al. Integrative genomics reveals frequent somatic NF1 mutations in sporadic pheochromocytomas. Hum Mol Genet. (2012) 21:5406-16. doi: $10.1093 / \mathrm{hmg} / \mathrm{dds} 402$

17. Dahia PL, Hao K, Rogus J, Colin C, Pujana MA, Ross K, et al. Novel pheochromocytoma susceptibility loci identified by integrative genomics. Cancer Res. (2005a) 65:9651-8. doi: 10.1158/0008-5472.CAN05-1427

18. Jochmanova I, Yang C, Zhuang Z, Pacak K. Hypoxia-inducible factor signaling in pheochromocytoma: turning the rudder in the right direction. J Natl Cancer Inst. (2013) 105:1270-83. doi: 10.1093/jnci/djt201

19. Lopez-Jimenez E, Gomez-Lopez G, Leandro-Garcia LJ, Munoz I, Schiavi F, Montero-Conde C, et al. Research resource: transcriptional profiling reveals different pseudohypoxic signatures in SDHB and VHL-related pheochromocytomas. Mol Endocrinol. (2010) 24:2382-91. doi: 10.1210/me.2010-0256

20. Walther MM, Keiser HR, Linehan WM. Pheochromocytoma: evaluation, diagnosis, and treatment. World J Urol. (1999) 17:35-9. doi: $10.1007 / \mathrm{s} 003450050102$

21. Mannelli M, Castellano M, Schiavi F, Filetti S, Giacche M, Mori L, et al. Clinically guided genetic screening in a large cohort of italian patients with pheochromocytomas and/or functional or nonfunctional paragangliomas. $J$ Clin Endocrinol Metab. (2009) 94:1541-7. doi: 10.1210/jc.2008-2419

22. Masson N, Willam C, Maxwell PH, Pugh CW, Ratcliffe PJ. Independent function of two destruction domains in hypoxia-inducible factor-alpha chains activated by prolyl hydroxylation. EMBO J. (2001) 20:5197-206. doi: $10.1093 / \mathrm{emboj} / 20.18 .5197$

23. Favier J, Briere JJ, Burnichon N, Riviere J, Vescovo L, Benit P, et al. The Warburg effect is genetically determined in inherited pheochromocytomas. PLoS ONE (2009) 4:e7094. doi: 10.1371/journal.pone.0007094

24. Kaelin WGJr, Ratcliffe PJ. Oxygen sensing by metazoans: the central role of the HIF hydroxylase pathway. Mol Cell (2008) 30:393-402. doi: 10.1016/j.molcel.2008.04.009

25. Young RM, Simon MC. Untuning the tumor metabolic machine: HIF-alpha: pro- and antitumorigenic? Nat Med. (2012) 18:1024-5. doi: 10.1038/nm.2865

26. Dahia PL, Ross KN, Wright ME, Hayashida CY, Santagata S, Barontini $\mathrm{M}$, et al. A HIF1alpha regulatory loop links hypoxia and mitochondrial signals in pheochromocytomas. PLoS Genet. (2005b) 1:72-80. doi: 10.1371/journal.pgen.0010008

27. Iommarini L, Porcelli AM, Gasparre G, Kurelac I. Non-canonical mechanisms regulating hypoxia-inducible factor 1 alpha in cancer. Front Oncol. (2017) 7:286. doi: $10.3389 /$ fonc. 2017.00286

28. Selak MA, Armour SM, MacKenzie ED, Boulahbel H, Watson DG, Mansfield KD, et al. Succinate links TCA cycle dysfunction to oncogenesis by inhibiting HIF-alpha prolyl hydroxylase. Cancer Cell (2005) 7:77-85. doi: 10.1016/j.ccr.2004.11.022

29. Favier J, Gimenez-Roqueplo AP. Pheochromocytomas: the (pseudo)-hypoxia hypothesis. Best Pract Res Clin Endocrinol Metab. (2010) 24:957-68. doi: $10.1016 /$ j.beem.2010.10.004 
30. Gimenez-Roqueplo AP, Favier J, Rustin P, Rieubland C, Kerlan V, Plouin PF, et al. Functional consequences of a SDHB gene mutation in an apparently sporadic pheochromocytoma. J Clin Endocrinol Metab. (2002) 87:4771-4. doi: $10.1210 /$ jc.2002-020525

31. Castro-Vega LJ, Buffet A, De Cubas AA, Cascon A, Menara M, Khalifa $\mathrm{E}$, et al. Germline mutations in $\mathrm{FH}$ confer predisposition to malignant pheochromocytomas and paragangliomas. Hum Mol Genet. (2014) 23:2440-6. doi: 10.1093/hmg/ddt639

32. Lorenzo FR, Yang C, Ng Tang Fui M, Vankayalapati H, Zhuang Z, Huynh T, et al. A novel EPAS1/HIF2A germline mutation in a congenital polycythemia with paraganglioma. J Mol Med (Berl) (2013) 91:507-12. doi: 10.1007/s00109-012-0967-z

33. Comino-Mendez I, de Cubas AA, Bernal C, Alvarez-Escola C, SanchezMalo C, Ramirez-Tortosa CL, et al. Tumoral EPAS1 (HIF2A) mutations explain sporadic pheochromocytoma and paraganglioma in the absence of erythrocytosis. Hum Mol Genet. (2013) 22:2169-76. doi: 10.1093/hmg/ddt069

34. Segouffin-Cariou C, Billaud M. Transforming ability of MEN2A-RET requires activation of the phosphatidylinositol 3-kinase/AKT signaling pathway. J Biol Chem. (2000) 275:3568-76. doi: 10.1074/jbc.275.5.3568

35. Land SC, Tee AR. Hypoxia-inducible factor 1alpha is regulated by the mammalian target of rapamycin (mTOR) via an mTOR signaling motif. J Biol Chem. (2007) 282:20534-43. doi: 10.1074/jbc.M611782200

36. Jiang S, Dahia PL. Minireview: the busy road to pheochromocytomas and paragangliomas has a new member, TMEM127. Endocrinology (2011) 152:2133-40. doi: 10.1210/en.2011-0052

37. Jimenez RH, Lee JS, Francesconi M, Castellani G, Neretti N, Sanders JA, et al. Regulation of gene expression in hepatic cells by the mammalian Target of Rapamycin (mTOR). PLoS ONE (2010) 5:e9084. doi: 10.1371/journal.pone.0009084

38. Crona J, Delgado Verdugo A, Maharjan R, Stalberg P, Granberg D, Hellman $\mathrm{P}$, et al. Somatic mutations in H-RAS in sporadic pheochromocytoma and paraganglioma identified by exome sequencing. J Clin Endocrinol Metab. (2013) 98:E1266-1271. doi: 10.1210/jc.2012-4257

39. Bersten DC, Sullivan AE, Peet DJ, Whitelaw ML. bHLH-PAS proteins in cancer. Nat Rev Cancer (2013) 13:827-41. doi: 10.1038/nrc3621

40. Wang GL, Jiang BH, Rue EA, Semenza GL. Hypoxia-inducible factor 1 is a basic-helix-loop-helix-PAS heterodimer regulated by cellular O2 tension. Proc Natl Acad Sci USA. (1995) 92:5510-4. doi: 10.1073/pnas.92.12.5510

41. Kaelin WG Jr. Cancer and altered metabolism: potential importance of hypoxia-inducible factor and 2-oxoglutarate-dependent dioxygenases. Cold Spring Harb Symp Quant Biol. (2011) 76:335-45. doi: $10.1101 /$ sqb.2011.76.010975

42. Zhikrivetskaya SO, Snezhkina AV, Zaretsky AR, Alekseev BY, Pokrovsky AV, Golovyuk AL, et al. Molecular markers of paragangliomas/pheochromocytomas. Oncotarget (2017) 8:25756-82. doi: 10.18632/oncotarget.15201

43. Jochmanova I, Zelinka T, Widimsky JJr, Pacak K. HIF signaling pathway in pheochromocytoma and other neuroendocrine tumors. Physiol Res. (2014) 63(Suppl. 2):S251-262.

44. Lee S, Nakamura E, Yang H, Wei W, Linggi MS, Sajan MP, et al. Neuronal apoptosis linked to EgIN3 prolyl hydroxylase and familial pheochromocytoma genes: developmental culling and cancer. Cancer Cell (2005) 8:155-67. doi: 10.1016/j.ccr.2005.06.015

45. Kondo K, Kim WY, Lechpammer M, Kaelin WGJr. Inhibition of HIF2alpha is sufficient to suppress pVHL-defective tumor growth. PLoS Biol. (2003) 1:E83. doi: 10.1371/journal.pbio.0000083

46. Kondo S, Kubota S, Shimo T, Nishida T, Yosimichi G, Eguchi T, et al. Connective tissue growth factor increased by hypoxia may initiate angiogenesis in collaboration with matrix metalloproteinases. Carcinogenesis (2002) 23:769-76. doi: 10.1093/carcin/23.5.769

47. Loenarz C, Coleman ML, Boleininger A, Schierwater B, Holland PW, Ratcliffe PJ, et al. The hypoxia-inducible transcription factor pathway regulates oxygen sensing in the simplest animal, Trichoplax adhaerens. EMBO Rep. (2011) 12:63-70. doi: 10.1038/embor.2010.170

48. Mills DB, Francis WR, Vargas S, Larsen M, Elemans CP, Canfield DE, et al. The last common ancestor of animals lacked the HIF pathway and respired in low-oxygen environments. Elife (2018) 7:e31176. doi: 10.7554/eLife.31176
49. Rosbash M. The implications of multiple circadian clock origins. PLoS Biol. (2009) 7:e62. doi: 10.1371/journal.pbio.1000062

50. Tarrant AM, Reitzel AM. Introduction to the symposium-keeping time during evolution: conservation and innovation of the circadian clock. Integr Comp Biol. (2013) 53:89-92. doi: 10.1093/icb/ict062

51. Egg M, Koblitz L, Hirayama J, Schwerte T, Folterbauer C, Kurz A, et al. Linking oxygen to time: the bidirectional interaction between the hypoxic signaling pathway and the circadian clock. Chronobiol Int. (2013) 30:510-29. doi: 10.3109/07420528.2012.754447

52. Wu D, Su X, Potluri N, Kim Y, Rastinejad F. NPAS1-ARNT and NPAS3-ARNT crystal structures implicate the bHLH-PAS family as multi-ligand binding transcription factors. Elife (2016) 5:e18790. doi: 10.7554/eLife.18790

53. Sharp B, Paquet E, Naef F, Bafna A, Wijnen H. A new promoter element associated with daily time keeping in Drosophila. Nucleic Acids Res. (2017) 45:6459-70. doi: 10.1093/nar/gkx268

54. Adamovich Y, Ladeuix B, Golik M, Koeners MP, Asher G. Rhythmic oxygen levels reset circadian clocks through HIF1alpha. Cell Metab. (2017) 25:93-101. doi: 10.1016/j.cmet.2016.09.014

55. Wu Y, Tang D, Liu N, Xiong W, Huang H, Li Y, et al. Reciprocal regulation between the circadian clock and hypoxia signaling at the genome level in mammals. Cell Metab. (2017) 25:73-85. doi: 10.1016/j.cmet.2016.09.009

56. Pelster B, Egg M. Multiplicity of hypoxia-inducible transcription factors and their connection to the circadian clock in the zebrafish. Physiol Biochem Zool. (2015) 88:146-57. doi: 10.1086/679751

57. Jensen LD, Cao Y. Clock controls angiogenesis. Cell Cycle (2013) 12:405-8. doi: $10.4161 /$ cc. 23596

58. Jensen LD, Cao Z, Nakamura M, Yang Y, Brautigam L, Andersson P, et al Opposing effects of circadian clock genes bmall and period 2 in regulation of VEGF-dependent angiogenesis in developing zebrafish. Cell Rep. (2012) 2:231-41. doi: 10.1016/j.celrep.2012.07.005

59. Rutter J, Reick M, Wu LC, McKnight SL. Regulation of clock and NPAS2 DNA binding by the redox state of NAD cofactors. Science (2001) 293:510-4. doi: 10.1126/science.1060698

60. Walton ZE, Patel CH, Brooks RC, Yu Y, Ibrahim-Hashim A, Riddle M, et al. Acid suspends the circadian clock in hypoxia through inhibition of mTOR. Cell (2018) 174:72-87.e32. doi: 10.1016/j.cell.2018.05.009

61. Okamura H. Integration of molecular rhythms in the mammalian circadian system. Novartis Found Symp. (2003) 253:161-170, discussion 102-169, 28164.

62. Fu L, Kettner NM. The circadian clock in cancer development and therapy. Prog Mol Biol Transl Sci. (2013) 119:221-82. doi: 10.1016/B978-0-12-396971-2.00009-9

63. Sahar S, Sassone-Corsi P. Metabolism and cancer: the circadian clock connection. Nat Rev Cancer (2009) 9:886-96. doi: 10.1038/nrc2747

64. Schernhammer ES, Laden F, Speizer FE, Willett WC, Hunter DJ, Kawachi I, et al. Night-shift work and risk of colorectal cancer in the nurses' health study. J Natl Cancer Inst. (2003) 95:825-8. doi: 10.1093/jnci/95.11.825

65. Shostak A. Circadian clock, cell division, and cancer: from molecules to organism. Int J Mol Sci. (2017) 18: E873. doi: 10.3390/ijms18040873

66. Causton HC, Feeney KA, Ziegler CA, O'Neill JS. Metabolic cycles in yeast share features conserved among circadian rhythms. Curr Biol. (2015) 25:105662. doi: 10.1016/j.cub.2015.02.035

67. Relogio A, Thomas P, Medina-Perez P, Reischl S, Bervoets S, Gloc E, et al. Rasmediated deregulation of the circadian clock in cancer. PLoS Genet. (2014) 10:e1004338. doi: 10.1371/journal.pgen.1004338

68. Hwang-Verslues WW, Chang PH, Jeng YM, Kuo WH, Chiang PH, Chang YC, et al. Loss of corepressor PER2 under hypoxia up-regulates OCT1-mediated EMT gene expression and enhances tumor malignancy. Proc Natl Acad Sci USA. (2013) 110:12331-6. doi: 10.1073/pnas.1222684110

69. Shostak A, Ruppert B, Ha N, Bruns P, Toprak UH, Project IM-S, et al. MYC/MIZ1-dependent gene repression inversely coordinates the circadian clock with cell cycle and proliferation. Nat Commun. (2016) 7:11807. doi: $10.1038 /$ ncomms11807

70. Bialas M, Dyduch G, Dudala J, Bereza-Buziak M, Hubalewska-Dydejczyk A, Budzynski A, et al. Study of microvessel density and the expression of vascular endothelial growth factors in adrenal gland pheochromocytomas. Int J Endocrinol. (2014) 2014:104129. doi: 10.1155/2014/104129 
71. Masri S, Papagiannakopoulos T, Kinouchi K, Liu Y, Cervantes M, Baldi P, et al. Lung adenocarcinoma distally rewires hepatic circadian homeostasis. Cell (2016) 165:896-909. doi: 10.1016/j.cell.2016.04.039

72. Zelinka T, Strauch B, Pecen L, Widimsky JJr. Diurnal blood pressure variation in pheochromocytoma, primary aldosteronism and Cushing's syndrome. $J$ Hum Hypertens (2004) 18:107-11. doi: 10.1038/sj.jhh.1001644

73. Nicholls MG, Espiner EA, Ikram H, Maslowski AH, Hamilton EJ, Bones PJ. Hormone and blood pressure relationships in primary aldosteronism. Clin Exp Hypertens A (1984) 6:1441-58.

74. Spieker C, Barenbrock M, Rahn KH, Zidek W. Circadian blood pressure variations in endocrine disorders. Blood Press (1993) 2:35-9. doi: 10.3109/08037059309077524

75. Marrone O, Riccobono L, Salvaggio A, Mirabella A, Bonanno A, Bonsignore MR. Catecholamines and blood pressure in obstructive sleep apnea syndrome. Chest (1993) 103:722-7. doi: 10.1378/chest.103.3.722

76. Pepine CJ. Circadian variations in myocardial ischemia. Implications for management JAMA (1991) 265:386-90.

77. Munakata M, Aihara A, Imai Y, Noshiro T, Ito S, Yoshinaga K. Altered sympathetic and vagal modulations of the cardiovascular system in patients with pheochromocytoma: their relations to orthostatic hypotension. Am J Hypertens (1999) 12:572-80. doi: 10.1016/S0895-7061(99)00 026-6

78. Streeten DH, Anderson GHJr. Mechanisms of orthostatic hypotension and tachycardia in patients with pheochromocytoma. Am J Hypertens (1996) 9:760-9. doi: 10.1016/0895-7061(96)00057-X

79. Bravo EL. Evolving concepts in the pathophysiology, diagnosis, and treatment of pheochromocytoma. Endocr Rev. (1994) 15:356-68. doi: 10.1210/edrv-15-3-356

80. Crout JR, Sjoerdsma A. Turnover and metabolism of catecholamines in patients with pheochromocytoma. J Clin Invest. (1964) 43:94-102. doi: $10.1172 /$ JCI104898

81. Pacak K. Phaeochromocytoma: a catecholamine and oxidative stress disorder. Endocr Regul. (2011) 45:65-90.
82. Eisenhofer G, Huynh TT, Elkahloun A, Morris JC, Bratslavsky G, Linehan WM, et al. Differential expression of the regulated catecholamine secretory pathway in different hereditary forms of pheochromocytoma. Am Physiol Endocrinol Metab. (2008) 295:E1223-33. doi: 10.1152/ajpendo.90591.2008

83. Imai Y, Abe K, Miura Y, Nihei M, Sasaki S, Minami N, et al. Hypertensive episodes and circadian fluctuations of blood pressure in patients with phaeochromocytoma: studies by long-term blood pressure monitoring based on a volume-oscillometric method. J Hypertens (1988) 6:9-15. doi: 10.1097/00004872-198801000-00003

84. Timmers HJ, Pacak K, Huynh TT, Abu-Asab M, Tsokos M, Merino MJ, et al. Biochemically silent abdominal paragangliomas in patients with mutations in the succinate dehydrogenase subunit B gene. J Clin Endocrinol Metab. (2008) 93:4826-32. doi: 10.1210/jc.2008-1093

85. Masoud GN, Li W. HIF-1alpha pathway: role, regulation and intervention for cancer therapy. Acta Pharm Sin B (2015) 5:378-89. doi: 10.1016/j.apsb.2015.05.007

86. Cuvillier O. The therapeutic potential of HIF-2 antagonism in renal cell carcinoma. Transl Androl Urol. (2017) 6:131-3. doi: 10.21037/tau.2017.01.12

87. Scheuermann TH, Li Q, Ma HW, Key J, Zhang L, Chen R, et al. Allosteric inhibition of hypoxia inducible factor- 2 with small molecules. Nat Chem Biol. (2013) 9:271-6. doi: 10.1038/nchembio.1185

Conflict of Interest Statement: The authors declare that the research was conducted in the absence of any commercial or financial relationships that could be construed as a potential conflict of interest.

Copyright (c) 2018 Tabebi, Söderkvist and Jensen. This is an open-access article distributed under the terms of the Creative Commons Attribution License (CC BY). The use, distribution or reproduction in other forums is permitted, provided the original author(s) and the copyright owner(s) are credited and that the original publication in this journal is cited, in accordance with accepted academic practice. No use, distribution or reproduction is permitted which does not comply with these terms. 